\title{
ÖGUM zertifizierter Basiskurs „Notfallsonografie“
}

Von 1. bis 2. Juli 2016 veranstaltete die Tiroler Arbeitsgemeinschaft für Notfallmedizin bereits zum 2. Mal nach 2015 einen ÖGUM zertifizierten Ultraschallworkshop „Basiskurs Notfallsonografie“.

Der Kurs, welcher im Thermenhotel in Längenfeld/Tirol stattgefunden hat, war in kürzester Zeit mit 40 Teilnehmern ausgebucht. Namhafte Gerätehersteller stellten uns neueste Technologien für das Hands-On zur Verfügung.

Da der Kurs sehr praxisorientiert ausgelegt war, wurde in zahlreichen Kleingruppen das Spektrum der Notfallsonografie gemeinsam mit fachkundigen Tutoren erarbeitet.

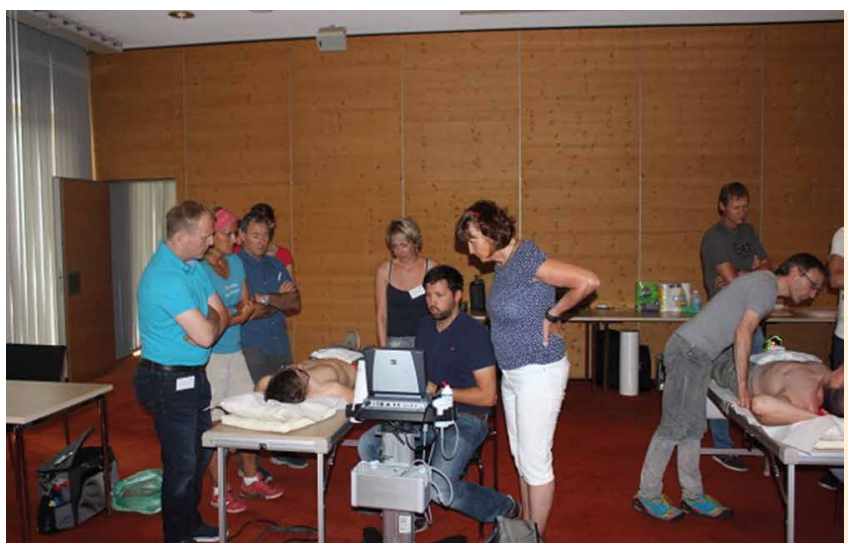

In Kleingruppen hatten die Teilnehmer während des Hands-On die Möglichkeit unterschiedliche Sonografiegeräte kennenzulernen.

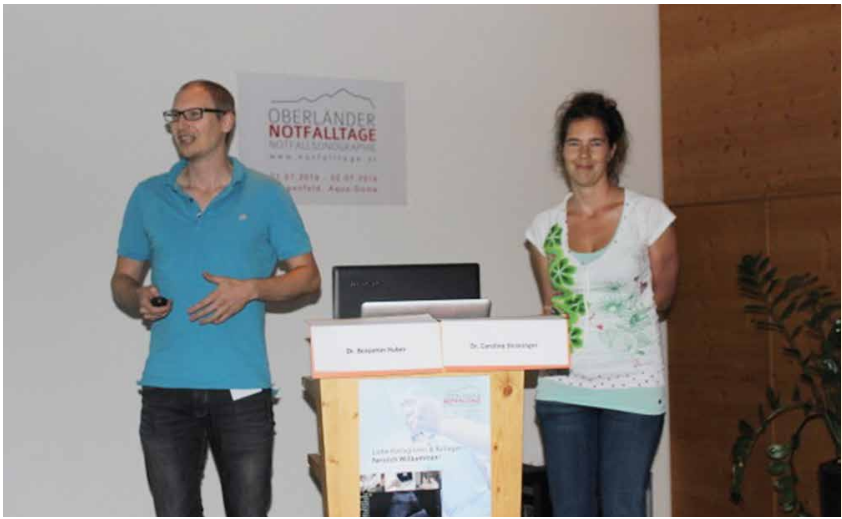

Dr. Huber und Dr. Straninger (Allgemeinmediziner Pfunds / Tirol) referieren über „Ultraschall aus der Praxis für die Praxis“
Die verschiedenen Blickwinkel auf die Notfallsonografie hat die Relevanz einer fundierten Sonografie-Ausbildung wieder aufgezeigt. Denn nicht nur im Schockraum im Krankenhaus zählt die Ultraschalldiagnostik mittlerweile zur Basisuntersuchung, auch im extramuralen Bereich, wo Allgemeinmediziner und/oder Notärzte rasche Entscheidungen treffen müssen, bietet die Möglichkeit einer Ultraschalluntersuchung ein relevante Entscheidungshilfe.

Durch die extrem rasche technische Entwicklung am Ultraschallsektor werden die mobilen Geräte immer kleiner und leichter mit gleichzeitig stetig steigender Bildqualität und Bedienerfreundlichkeit.

Motiviert durch das positive Feedback der Teilnehmer, Referenten und Tutoren werden wir im nächsten Jahr im Rahmen der Oberländer Notfalltage (9.-11.6.2017) die Notfallsonografie als erweitertes Tool der präklinischen Diagnostik als Praxisstation einbauen.

Auch wird es im Rahmen dieser Veranstaltung möglich sein das „final teaching“ zu absolvieren und das Zertifikat „Notfallso- 


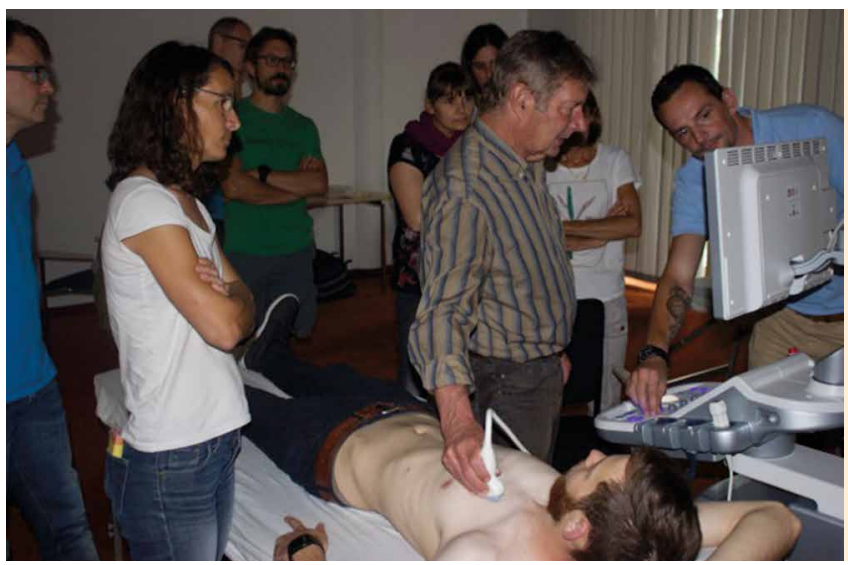

Prof. Gebhard Mathis (Leiter ÖGUM Arbeitskreis „Notfallmedizin) stand als Ultraschallexperte mit Rat und Tat zur Seite

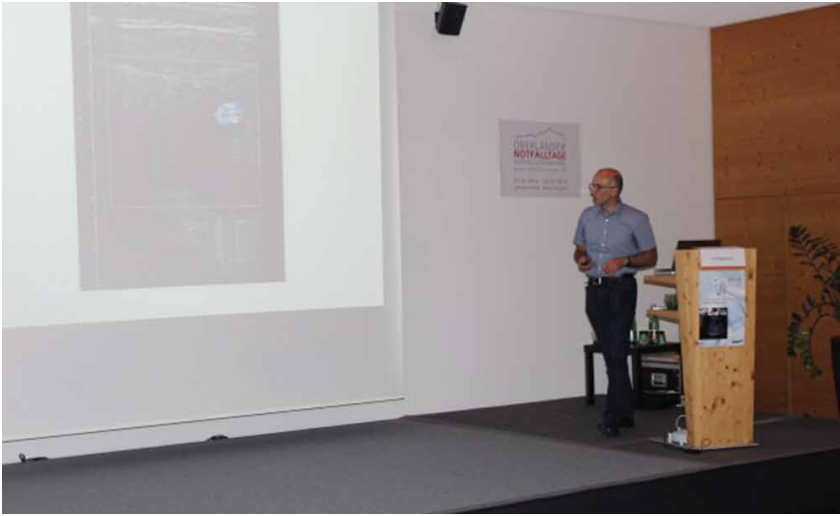

Dr. Wolfgang Sturm (stv. ÖGUM-Arbeitskreisleiter Abdomen) berichtete über Aortenaneurysma und -dissektion.

nografie“ der ÖGUM zu erwerben. Die Voraussetzung dafür sind der Basiskurs Notfallsonografie und die geforderte Anzahl an dokumentierten Untersuchungen.

Aufgrund des regen Interesses und der insgesamt sehr positiv aufgenommenen Workshops planen wir für 2018 wieder einen Basiskurs Notfallsonografie. Nähere Informationen finden Sie unter: www. notfalltage.at

Dr. Ralph Faschingbauer - ÖGUM Mitglied 